\title{
Diagnosis of complicated grief using the texas revised inventory of grief, brazilian portuguese version
}

\begin{abstract}
Background: Complicated grief is characterized by persistent yearning for the deceased, intense sorrow and emotional pain in response to death causing significant distress. Complicated grief is often under recognized and undertreated. The Texas Revised Inventory of Grief (TRIG) is a questionnaire that has been demonstrated to have high validity and reliability in the assessment of grief. Our objective was to translate, adapt, and validate the TRIG to Brazilian Portuguese and to verify whether the TRIG, in a bereaved population, is able to distinguish between those with and those without complicated grief and to identify which elements in the scale contribute to this.
\end{abstract}

Methods: Two stages: a) cross-culture adaptation of a questionnaire, and b) cross-sectional study of reliability and validity.

Setting and Participants: 165 adult patients were recruited from a) the Grief Outpatient Clinic at the Department and Institute of Psychiatry - University of São Paulo, b) private practice at the same department, and c) co-workers who have lost a loved one. All the patients were interviewed with the TRIG. According to clinical criteria69 of 165 bereaved patients were presenting complicated grief.

Results: Cross-culture adaptation: the TRIG was translated from American English, then back-translated and finally compared with the Brazilian Portuguese version by two bilingual psychiatrists. Reliability: the Cronbach's alpha coefficients (internal consistency) of the TRIG scales were 0,735 (part I) and 0,896 (part II). Sensitivity, specificity as well as cutoff points to identify complicated and non-complicated grief, were measured using the ROC curve. Using the total score of 104 (part I + part II + Part III + psychographics variables), we can correctly classify $71.3 \%$ of individuals with and without complicated grief. The construct validity was assessed by factor analysis and confirmatory analysis. Furthermore, by logistic regression, our study demonstrated that a low education level, age of the deceased and age of the bereaved, loss of a son or daughter, and unexpected death were all risk factors for complicated grief. Our results also suggest that religion may influence complicated grief.

Conclusion: The TRIG adapted to Brazilian Portuguese is as reliable and valid as the original version. In the evaluation of Brazilian bereaved, it was able to distinguish individuals with and without complicated grief. And, we suggest a cut-off value of 104 for complicated grief.

Keywords: bereavement, complicated grief, brazilian portuguese version of the texas revised inventory of grief (trig), reliability and validity
Volume 6 Issue I - 2016

\author{
Alves TM,' Oliveira MC, ${ }^{2}$ Lotufo Neto $\mathrm{F}^{3}$ \\ 'Department and Institute of Psychiatry, University of Sao Paulo, \\ Brazil \\ ${ }^{2}$ Institute of Mathematics and Statistics, University of Sao Paulo, \\ Brazil \\ ${ }^{3}$ Department and Institute of Psychiatry, University of Sao Paulo, \\ Brazil
}

Correspondence: Tania Maria Alves, Av. Dr. Ovidio Pires de Campos, 795, Cerqueira Cesar, 05403-010, Sao Paulo, SP, Brazil, Email tanalves@uol.com.br

Received: October 29, 2015 | Published: May 25, 2016

\section{Introduction}

The loss or deprivation of a loved one, especially by death, is consistently described as one of the most stressful life events, greatly affecting physical, social and psychological welfare. ${ }^{1}$ The reactions to the work of mourning do not always follow a normal course ${ }^{2}$ and, in this article, when excessively intense or prolonged will be called complicated grief (CG). To find a direct measure of the intensity of grief, in 1977, Faschingbauer et al., ${ }^{3}$ developed the 'Texas Inventory of Grief (TIG)', which was expanded in 1981 to be the Texas Revised Inventory of Grief (TRIG), when it reached its final model by Exploratory Factor Analysis (EFA) with varimax rotation. ${ }^{4}$ The authors evaluated a series of past and present thoughts related to the loss, emotions and behaviors to evaluate changes in grief reactions. In this sense, it is highly specific and restricted to the theme. From their data it was possible to gather information, group symptoms in clusters, adjust and compare them to other information to establish the diagnostic criteria for complicated grief, which has been viewed separately from symptoms of depression, adjustment reaction, acute stress reaction and post-traumatic stress disorder ${ }^{5-10}$. This instrument is the best known and most widely used as a measure of mourning. ${ }^{11}$ Cross-cultural adaptation of TRIG has been undertaken to German, ${ }^{12}$ French, ${ }^{13}$ Spanish ${ }^{14}$ and Turkish. ${ }^{15}$ Additional validation in different cultures is needed to establish the benefit of these measures as a substitute for clinical judgment or categories created without benchmark. In 2008, Barros ${ }^{16}$ began the process of validation of TRIG for Portuguese in a population of bereaved parents suffering the loss of a child due to pediatric cancer. In this dissertation, some questions were adapted for this specific population and good internal consistency was achieved, measured by Cronbach's Alpha coefficient. Motivated to find out whether the TRIG would be able to distinguish the bereaved with and without complicated grief, we continued the validation process with a sample closer to the one used in the original conditions of the instrument. 


\section{Objectives}

To adapt the Texas Revised Inventory of Grief (TRIG) of Faschinbaguer et al., ${ }^{3,4}$ to Brazilian Portuguese and examine its reliability and validity. To verify whether the TRIG, in a bereaved population, is able to distinguish between those with and those without complicated grief and to identify which elements in the scale contribute to this.

\section{Methods}

Ethics statement: The ethical and scientific validity of this study was approved by the institutional review board of the University of São Paulo - Brazil.

Participants and procedures: adult patients were recruited from a) the Grief Outpatient Clinic at the Department and Institute of Psychiatry - University of São Paulo, b) private practice at the same site, and c) co-workers who have lost a loved one, were not undergoing psychiatric treatment and who agreed to participate in the study. The inclusion criterion was having a close relationship with the deceased loved one. Initially, a sample consisting of 165 subjects was defined based on the literature about validation of TRIG. ${ }^{3,11,13,14}$ The statistical analysis was undertaken by the software GPower 3.1, which showed that 94 cases would be a minimum and sufficient number to estimate the difference between the groups with and without complicated grief with a reliability coefficient of $95 \%$. All data were collected from July2011 to December2013.

Instrument: TRIG, Brazilian Portuguese version, was used to collect socio- demographic data and as a measure of mourning. It was applied to all in a single interview, completed by the respondents and the interviewer (TMA) could answer questions if asked.

\section{Cross-cultural adaptation}

The study was conducted based on systematizations, ${ }^{17-22}$ i.e., according to the following steps:

a. Translation by a psychiatrist and an English teacher, both bilingual;

b. Back-translation by a bilingual English teacher blind to the English translation process;

c. Comparison, consensus and style review by a group of bilingual judges who examined the two versions and

d. Implementation on a pilot sample and review for final adjustments.

Before this whole process, we obtained the permission of the original authors.

\section{Statistical method}

For assessment of reliability and internal consistency of the TRIG, Cronbach's Alpha coefficient and item-total correlations were used. To test the validity of the criterion, subjects with complicated grief were those who clinically experienced the loss of a beloved one with typical symptoms of bereavement (e.g. yearning to search for the deceased, avoiding memories of the deceased, feelings of void and disbelief in life or difficulty to accept the death of the deceased) and intense psychological suffering associated with the presence of complications of physical and/or mental health, as described below.

a. Suicide risk: presence of suicide 'ideation', 'planning' or 'actual attempt' triggered by the mourning process. If the desire of their own death was ascribed to God or fate, then it was not considered as a criterion, and b. Aggravation of pre-existing illness/es or the emergence of one or more, be it/they physical, psychological or mental.

The homogeneity between the groups with and without complicated grief (WCG) was assessed through the chi-square test for categorical variables and for the others, the t-test for parametric variables and the Mann-Whitney test for nonparametric variables. The KolmogorovSmirnov test was used to identify whether the quantitative variables could be approximated for normal distribution. Multivariate analyzes were performed using logistic regression.

\section{Criterion validity}

From the clinical criteria established for complicated grief (our gold standard) it was assessed whether TRIG alone could distinguish the same groups, i.e. those with complicated grief from those without it. The TRIG was divided into four parts and, for each answer, values were ascribed to the variables. Namely; Part I, consisting of 8 items and a maximum total score of 40, explores the behavior and feelings of the bereaved immediately after the loss; Part II, consisting of 13 items and a maximum score of 65 , explores the current feelings of the bereaved towards the deceased. Both parts have five categories of response (Likert type), ranging from 'completely true' (5 points) to 'completely false' (1 point); Part III, consisting of 5 items, evaluates issues related to mourning and has two categories of response, 'true' (5 points) and 'false' ( 1 point) with reversed scores for the items 'I attended the funeral of the person who died' and 'I feel I am now functioning about as well as I was before the death'. And Part IV consists of two items: a) 'Looking back, I would guess that my relationship with this person was: 'closer than any relationship I've ever had before or since' (5 points), 'Closer than most relationships I've had with other people' (4 points), 'About as close as most of my relationships with others' (3 points), 'Not as close as most of my relationships with others' ( 2 points) and 'Not very close at all' (1 point), and b) 'This person's death was: 'Expected or slow' (1 point) and 'Unexpected or sudden' (5 points). For their evaluation, the scores on each item were summed up and the totals of each of its 4 parts were calculated. To calculate the sensitivity and specificity the most appropriate point was sought from which complicated grief is distinguished from uncomplicated grief in the area under the ROC curve. From the maximization of sensitivity and specificity found, the cut-off points could be identified to define strong points and Binary Logistic Regression was used to identify which of the TRIG variables contributed to differentiate between CG and WLC groups.

\section{Construct validation}

in order to assess whether TRIG contained variables which were highly correlated and could be grouped together and taken as a whole as a measure of one same construct, Exploratory Factor Analysis (EFA), using principal components (varimaxrotation) was under taken. Confirmatory factor analysis (CFA), was conducted to validate the factors found in the EFA and its co variances. The level of significance considered was 5\%, in statistical package SPSS (version 14) and AMOS (version 16).

\section{Results}

165 patients were included, 69 with complicated grief (CG) and 96 without complicated grief (WCG). No significant differences in sociodemographic variables were found between the groups. The sample predominantly came from the mourning outpatient ambulatory clinic (68\%), female (84\%), Catholic (53\%), white (61\%) and the mourner's current age was $48.96 \pm 14.82$ years (mean $\pm \mathrm{SD}$ ). There was a significant difference between groups in terms of years of education, with $11.77 \pm 4.71$ years in the WCG group and $9.43 \pm 4.97$ for CG (p $=0.002)$. 
Table I Characteristics at berearement

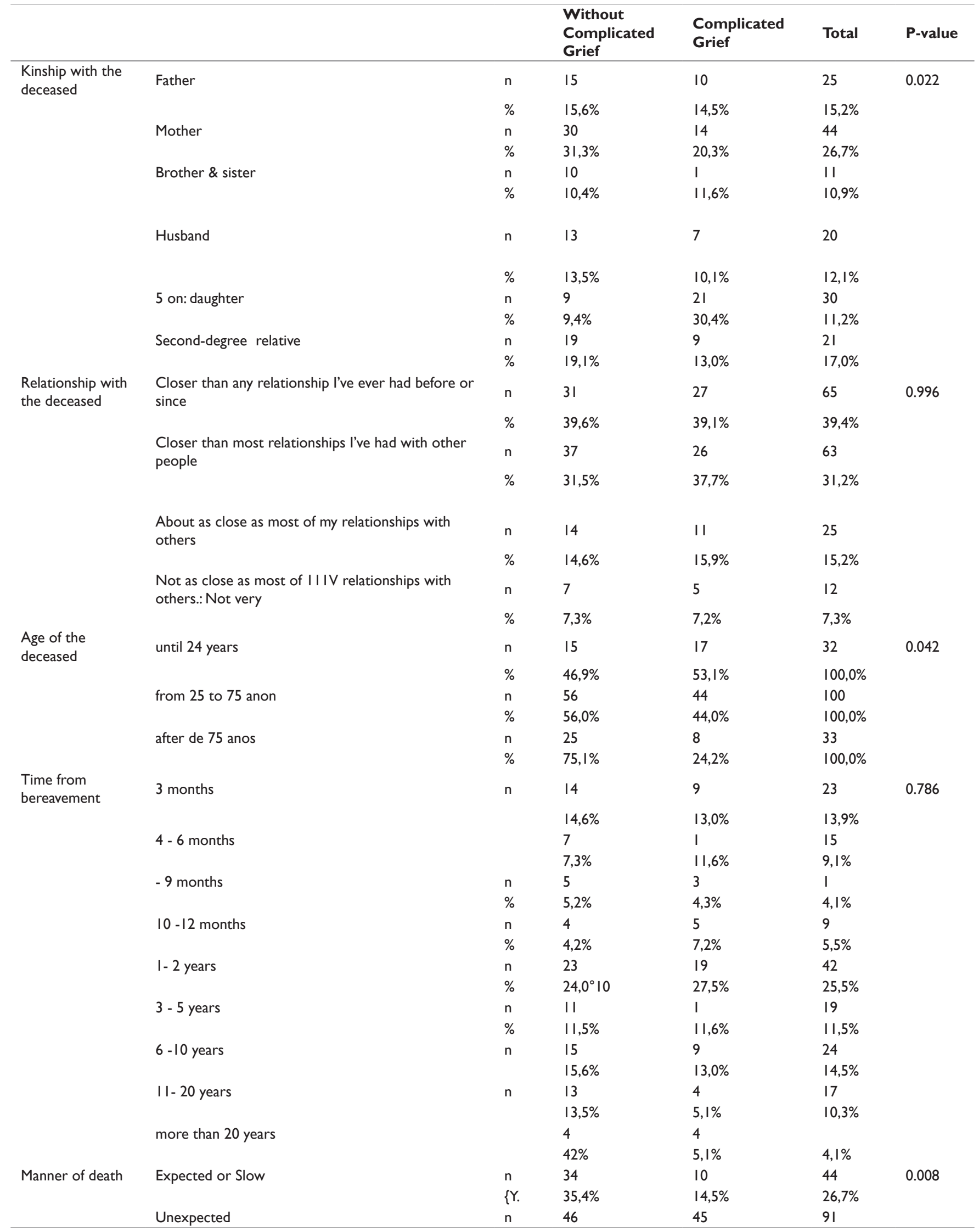


Table Continued..

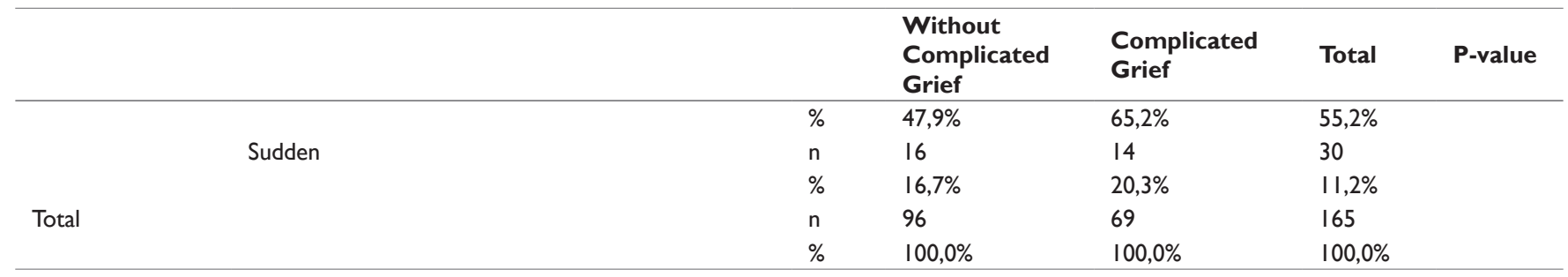

Table 2 Frequency of clinical and mental illness in the sample

\begin{tabular}{|c|c|c|c|c|c|}
\hline & & & $\begin{array}{l}\text { Without } \\
\text { Complicated } \\
\text { Grief }\end{array}$ & $\begin{array}{l}\text { With } \\
\text { Complicated } \\
\text { Grief }\end{array}$ & Total \\
\hline \multirow[t]{10}{*}{ Mental illness } & Depression & Not Developed & $83(86 \%)$ & $23(33 \%)$ & $106(64 \%)$ \\
\hline & & worsened preexisting condition & $0(\%)$ & $3(4 \%)$ & $3(2 \%)$ \\
\hline & Alciahnlism & Not Developed & 93 (97\%) & $62(90 \%)$ & $155(94 \%)$ \\
\hline & & Developed & $3(3 \%)$ & $3(4 \%)$ & $6(4 \%)$ \\
\hline & Smoking & Not Developed & 92 (96\%) & $56(81 \%)$ & $148(90 \%)$ \\
\hline & & Developed & $0(\%)$ & I [ [I\%) & I (I\%) \\
\hline & & worsened preexisting condition & $4(4 \%)$ & $12[17 \%)$ & $16(10 \%)$ \\
\hline & Other mental disorder & Not Developed & 84 (88\%) & $53(77 \%)$ & $137(83 \%)$ \\
\hline & & Developed & II (II\%) & $13(19 \%)$ & $24(15 \%)$ \\
\hline & & worsened preexisting condition & I (I\%) & $3(4 \%)$ & $4(2 \%)$ \\
\hline \multirow{18}{*}{ Clinical diseases } & & Developed & $6(6 \%)$ & $4(6 \%)$ & $10(6 \%)$ \\
\hline & & worsened preexisting condition & $0(\%)$ & I (I\%) & I (I\%) \\
\hline & Cardiovascular & Not Developed & 89 (93\%) & $59(86 \%)$ & I 43 (90\%) \\
\hline & & Developed & 7 (7\%) & $10(14 \%)$ & 17 (10\%) \\
\hline & Gastrointestinal & Not Developed & $96[100 \%)$ & $42(61 \%)$ & 138 (84\%) \\
\hline & & Developed & $0(\%)$ & $26(38 \%)$ & $26(16 \%)$ \\
\hline & & worsened preexisting condition & $0(\%)$ & I (I\%) & I (I\%) \\
\hline & Dermatological & Not Developed & 92 (96\%) & $65(94 \%)$ & 157 (95\%) \\
\hline & & Developed & $4(4 \%)$ & $4(6 \%)$ & $8(5 \%)$ \\
\hline & Rheumatologic & Not Developed & $96(100 \%)$ & $66(96 \%)$ & $162(98 \%)$ \\
\hline & & Developed & $0(\%)$ & I (I\%) & I (I\%) \\
\hline & & worsened preexisting condition & $0(\%)$ & $2(3 \%)$ & $2(1 \%)$ \\
\hline & Gynecological & Developed & 95 (99\%) & $63(91 \%)$ & $158(96 \%)$ \\
\hline & & Not Developed & I (I\%) & $6(9 \%)$ & 7 (4\%) \\
\hline & Respiratory & Not Developed & 91 (95\%) & 67 (97\%) & $158(96 \%)$ \\
\hline & & worsened preexisting condition & I (I\%) & I (I\%) & $2(1 \%)$ \\
\hline & Musculoskeletal & Not Developed & 94 (98\%) & $65(94 \%)$ & $159(96 \%)$ \\
\hline & & Developed & $2(2 \%)$ & $4(6 \%)$ & $6(4 \%)$ \\
\hline Total & & & $96(100 \%)$ & $69(100 \%)$ & $\begin{array}{l}165 \\
(100 \%)\end{array}$ \\
\hline
\end{tabular}

Table 3 Internal consistency analysis, sensitivity, specificity and cutoff of the TRIG

\begin{tabular}{|c|c|c|c|c|c|c|c|}
\hline & \multicolumn{7}{|l|}{ IC (95\%) ROC } \\
\hline & Cronbach's Alpha & ROC Curve Area & Lower & Upper & Cut-Off & Sensitivity & Specificity \\
\hline Total score of part I & 0,735 & 0,643 & 0,558 & 0,728 & 27 & 0,618 & 0,663 \\
\hline Total score of parte II & 0,897 & 0,680 & 0,598 & 0,763 & 54 & 0,676 & 0,621 \\
\hline Total score of parte III & & $0,7 \mid 4$ & 0,635 & 0,793 & 15 & 0,809 & 0,547 \\
\hline Total score of parte IV & & 0,598 & $0,5 \mathrm{II}$ & 0,685 & 6 & 0,838 & 0,347 \\
\hline Total score (Parte I+II + III + IV) & 0,885 & 0,713 & 0,634 & 0,793 & 104 & 0,662 & 0,674 \\
\hline
\end{tabular}

Table 1 shows the characteristics related to mourning. In the CG group the percentage was 3 times higher when the deceased was a son or a daughter than any other family relationship $(\mathrm{p}=0.022)$. The average age of the deceased in this sample was $55.80 \pm 24.46$ years in the WCG and $46.97 \pm 24.35$ in the CG group $(\mathrm{p}=0.027)$.Logistic regression showed that the younger the deceased, the greater the risk of the bereaved developing complicated grief. And when the age of the deceased is above 75 , this becomes a protective factor, i.e., the risk for the bereaved to develop complicated grief decreases $(\mathrm{p}=0.042)$. 
Table 4 Multivariate Logistic Regression - Variables associated with Complicated Grief controlled by heteroscedasticfactors

\begin{tabular}{|c|c|c|c|c|c|c|}
\hline & \multirow{2}{*}{ Coef. Beta } & \multirow{2}{*}{ S.E. } & \multirow{2}{*}{ Sig. } & \multirow{2}{*}{ Odds ratio } & \multicolumn{2}{|c|}{ IC (95\%) Odds } \\
\hline & & & & & Lower & Upper \\
\hline Total score of Part I & 0,065 & 0,027 & 0,015 & $\mathrm{I}, 07$ & $\mathrm{I}, 0 \mathrm{I}$ & 1,12 \\
\hline Total score of Parte II & 0,054 & 0,016 & 0,001 & $\mathrm{I}, 06$ & 1,02 & 1,09 \\
\hline Total scare of Parte III & 0,198 & 0,046 & $<0,00$ I & $\mathrm{I}, 22$ & 1,12 & $\mathrm{I}, 33$ \\
\hline Total scare of Parte IV * & & & 0,786 & & & \\
\hline Total score Gera! (Parte I -F II + III + IV) & 0,041 & 0,010 & $<0,00$ l & $\mathrm{I}, 04$ & 1,02 & $\mathrm{I}, 06$ \\
\hline $\begin{array}{l}\text { I couldn't keep up with my normal activities for the } 3 \\
\text { months after this person died }\end{array}$ & 0,893 & 0,358 & 0,013 & 2,44 & $\mathrm{I}, 2 \mathrm{I}$ & 4,93 \\
\hline I found it hard to sleep after this person died & 1,165 & 0,409 & 0,004 & 3,20 & $\mathrm{I}, 44$ & 7,14 \\
\hline I still cry when I think of the person who died & 1,151 & 0,389 & 0,003 & 3,16 & $\mathrm{I}, 47$ & 6,78 \\
\hline I cannot accept this person's death & 1,075 & 0,343 & 0,002 & 2,93 & $\mathrm{I}, 50$ & 5,74 \\
\hline $\begin{array}{l}\text { Even now it's painful to recall memories of the } \\
\text { person who died }\end{array}$ & 1,103 & 0,552 & 0,046 & 3,01 & $\mathrm{I}, 02$ & 8,89 \\
\hline $\begin{array}{l}\text { I am preoccupied with thoughts (often think) about } \\
\text { the person who died }\end{array}$ & 0,753 & 0,338 & 0,026 & 2,12 & 1,09 & 4,12 \\
\hline $\begin{array}{l}\text { I hide my tears when I think about the person who } \\
\text { died }\end{array}$ & 0,793 & 0,339 & 0,019 & 2,21 & $\mathrm{I}, \mathrm{I4}$ & 4,29 \\
\hline $\begin{array}{l}\text { No one will ever take the place in my life of the } \\
\text { person who died I am unable to accept the death of } \\
\text { the person who died }\end{array}$ & $\mathrm{I}, 253$ & $0,54-8$ & 0,022 & 3,50 & $\mathrm{I}, 20$ & 10,24 \\
\hline $\begin{array}{l}\text { I am unable to accept the death of the person who } \\
\text { died }\end{array}$ & 0,850 & 0,334 & 0,011 & 2,34 & 1,22 & 4,50 \\
\hline $\begin{array}{l}\text { I feel that I have really grieved for the person who } \\
\text { died }\end{array}$ & I,582 & 0,680 & 0,020 & 4,86 & I,28 & 18,43 \\
\hline $\begin{array}{l}\text { I seem o get upset each year about the same time as } \\
\text { the person died }\end{array}$ & $\mathrm{I}, 387$ & 0,361 & 0,000 & 4,00 & I,97 & 8,12 \\
\hline $\begin{array}{l}\text { Sometimes, I feel that I have the same illness as the } \\
\text { person who died }\end{array}$ & I,338 & 0,391 & 0,001 & 3,81 & $\mathrm{I}, 77$ & 8,20 \\
\hline
\end{tabular}

Total score of Parte IV:There was not significant because it contains 'form of death', variable already used in all logistic regressions as.

Table 5 Exploratory factor analysis - factors of Parts I, II and III

\begin{tabular}{|c|c|c|c|c|}
\hline \multirow[t]{13}{*}{ Part I } & Components & $\begin{array}{l}\text { Factor I } \\
\text { (Depression) }\end{array}$ & Factor 2 & (Anger IJ) \\
\hline & need to do things that the deceased wanted & & 0,478 & \\
\hline & Angry that person who died left me & & 0,451 & \\
\hline & unusually irritable after this person died & & $-0,734$ & \\
\hline & hard to get along with certain people & 0,799 & & \\
\hline & couldn't keep up with my normal activities for the first 3 months & 0,799 & & \\
\hline & lost interest in my family, friends, and outside activities & 0,765 & & \\
\hline & hard to work well after this person died & 0,645 & & \\
\hline & hard to sleep after this person died & 0,551 & & \\
\hline & Kaiser-Meyer-Olkin Measure of Sampling Adequacy & 0,805 & & \\
\hline & Bartlett's Test of Sphericity & 252,427 & & \\
\hline & df & 28 & & \\
\hline & Sig & 0,000 & & \\
\hline \multirow[t]{12}{*}{ Part II } & Components & Factor I (Suffering) & $\begin{array}{l}\text { Factor } 2 \\
\text { (Anger II) }\end{array}$ & $\begin{array}{l}\text { Factor } 3 \\
\text { (Yearning) }\end{array}$ \\
\hline & still feel the need to cry for the person who died & 0,774 & & \\
\hline & can't avoid thinking about the person who died & 0,773 & & \\
\hline & still cry when I think about the person who died & 0,739 & & \\
\hline & preoccupied with thoughts (often think) about the person & 0,726 & & \\
\hline & hide my tears when I think about the person who died & 0,645 & & \\
\hline & $\begin{array}{l}\text { No one will ever take the place in my life of the person who } \\
\text { died }\end{array}$ & 0,578 & & \\
\hline & still get upset when I think about the person who died & 0,561 & & \\
\hline & it's painful to recall memories of the person who died & 0,542 & & \\
\hline & it's unfair that this person died & & 0,853 & \\
\hline & unable to accept the death of the person who died & & 0,851 & \\
\hline & cannot accept this person's death & & 0,728 & \\
\hline
\end{tabular}


Table Continued...

\begin{tabular}{|c|c|c|c|c|}
\hline \multirow[t]{7}{*}{ Part II } & Components & Factor I (Suffering) & $\begin{array}{l}\text { Factor } 2 \\
\text { (Anger II) }\end{array}$ & $\begin{array}{l}\text { Factor } 3 \\
\text { (Yearning) }\end{array}$ \\
\hline & Things and people around me still remind me of the person & & & 0,815 \\
\hline & Sometimes I very much miss the person who died & & & 0,735 \\
\hline & Kaiser-Meyer-Olkin Measure of Sampling Adequacy & 0,898 & & \\
\hline & Bartlett's Test of Sphericity & 1021,76 & & \\
\hline & df & 78 & & \\
\hline & Sig & 0,000 & & \\
\hline \multirow[t]{10}{*}{ Part III } & Components & $\begin{array}{l}\text { Factor I } \\
\text { (Awareness) }\end{array}$ & \multicolumn{2}{|c|}{ Factor 2 (Identification) } \\
\hline & to get upset each year at about the same time as the person died & 0,756 & & \\
\hline & I have really grieved for the person who died & 0,662 & & \\
\hline & I am now functioning about as well as I was before the death & $-0,748$ & & \\
\hline & I have the same illness as the person who died & & 0,657 & \\
\hline & attended the funeral of the person who died & & 0,776 & \\
\hline & Kaiser-Meyer-Olkin Measure of Sampling Adequacy & 61,000 & & \\
\hline & Bartlett's Test of Sphericity & 45,092 & & \\
\hline & df & 10 & & \\
\hline & Sig & 0,000 & & \\
\hline
\end{tabular}

\section{Reliability - internal consistency of the TRIG}

The Cronbach's Alpha coefficient was 0,735 (part I) and 0,896 (part II).

\section{Criterion validity}

69 individuals ( $42 \%$ of sample) could be distinguished, of which $35(21 \%)$ were not at risk of suicide but had physical or mental illness; $26(16 \%)$ at risk of suicide and mental illness, $5(3 \%)$ at risk of suicide, without physical or mental illness and $3(2 \%)$ at risk of suicide with physical illness and without mental illness. The physical and psychiatric illnesses found in this sample were diagnosed by experts from their respective fields and their frequency distribution between CG and WCG are presented in Table 2. 'Other mental disorder' grouped phobic anxiety disorders, post-traumatic stress disorder, somatoform disorders, dissociative disorders, mood disorders and acute and transient psychotic disorders. For the sample size it was calculated what would be the lowest number of subjects needed to find a significant difference between individuals with and without complicated grief from their average total score on the TRIG using the parameters: a) the maximum type I error (alpha) of 5\% and sample power of $95 \%$; b) considering the sample of two independent groups, i.e. with and without complicated grief; c) the variable of interest was the total score of TRIG (sum of Parts I, II, III and IV), considered nonparametric; and d) the percentage of subjects with complicated grief being $42 \%$ of the sample, i.e. a ratio between sample sizes of the groups of 0.718 . The minimum required sample size was 94 subjects, of which 55 did not have complicated grief and 39 had complicated grief.

The values of sensitivity, specificity, ROC curve area and the cut-off points for each part of the instrument are in Table 3. Then, to identify the variables that would be important to predict complicated grief, a Multivariate Logistic Regression was performed (Table 4) controlled by the variables that differentiated the two groups ('mode of death', 'age of the deceased', 'education of the bereaved' and 'kin of the deceased as a son or a daughter'). All variables of Parts I, II, III and IV of the instrument and their totals, religion, gender of the bereaved and all variables that were significant in the univariate analysis were entered into the model.

\section{Construct validity}

The Exploratory Factor Analysis revealed seven factors, as shown in Table 5. Next, we tested the seven-factor model by confirmatory factor analysis and two robust factors emerged called 'Suffering' and 'Depression'(Table 6). The goodness-of-fit indexes were sufficient $(\mathrm{CMIN}=20.244, \mathrm{CMIND} / \mathrm{DF}=0.843, \mathrm{GFI}=0.973, \mathrm{NFI}=0.965$, $\mathrm{CFI}=1.000, \mathrm{TLI}=1.01, \mathrm{RMSEA}=0,000, \mathrm{AIC}=62.244$ and $\mathrm{BIC}=$ 127.469).

Table 6 Confirmatory Analysis - best fit to the factors found in the factor analysi

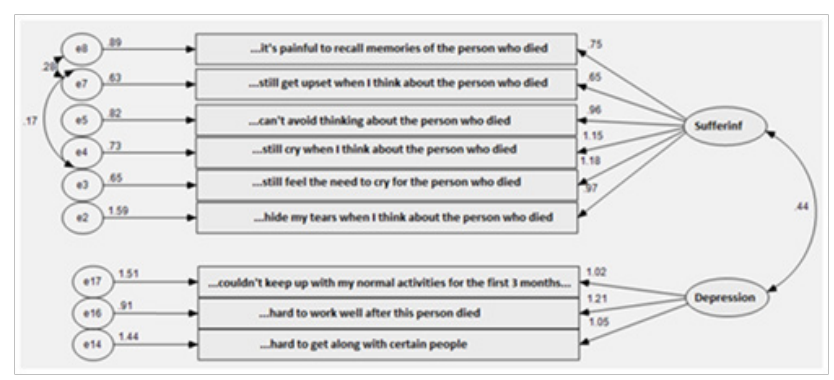

\section{Discussion}

\section{As for the translation and adaptation process to Portuguese}

The technical equivalence was reached by using the same methods of data collection adopted in the culture of origin, i.e., application in population's at various periods of mourning, and assessing subjects undergoing and not undergoing specific treatment for mourning, thus ensuring that mild to severe cases were included. For Semantic Equivalence the following adjustments were made. In the original version the phrase "PLEASE COMPLETE A SEPARATE FORM FOR EACH PERSON WHO DIED' came after the first psychographic data. We brought it forward so that all psychographic questions would consider this information; the question 'THIS PERSON DIED...' had overlapping alternatives regarding time intervals in the original version, so were defined them. In the pilot study, in the question 'LOOKING BACK, I WOULD GUESS THAT MY RELATIONSHIP WITH THIS PERSON WAS...' we have opted for the word 'íntima' 
for 'closer' in the original version. This aroused doubts in the respondent as to whether it contained an erotic or sexual reference, so it was changed to 'próxima', which had good acceptance and provided clarification of its meaning. The end result is in Annex 1.

The prevalence of bereaved subjects with $\mathrm{CG}$ in this sample was $42 \%$, different from that observed in the general population, which ranges from $2.4 \%{ }^{23}$ to $6.7 \%{ }^{24}$ and, in older people, $25 \%{ }^{25}$ This was similar to the frequency of $44.3 \%$ recorded by Shear et al. ${ }^{26}$ The risk factors for the bereaved developing complicated grief in this sample were low education, age of the deceased (the younger the deceased, the greater the risk of the mourner developing complicated grief), the deceased being a son or a daughter (suggesting that the significant impact for the CG group was due to the disruption of the natural and expected order by which the death of parents precedes the death of their children), the mode of the deceased's death being sudden or unexpected, and the total score being equal or above 104. Both groups CG and WCG showed significant improvement in symptoms (decrease in the total score of Part II) after 10years since the loss, with improvement peak times of 7-9months, 1-2years and 3-5years. The CG group experienced severe symptoms, i.e., those with complicated grief always have higher scores and this difference is maintained over time, confirming the findings of Zisook, ${ }^{27}$ by which many symptoms and behaviors related to grief remain present for years, perhaps indefinitely. According to the results obtained and in compliance with Delalibera et al., ${ }^{28}$ in our population, the criterion of time does not have the relevance ascribed to it by Prigerson.

\section{As for reliability}

The TRIG - Brazilian Portuguese version achieved good internal consistency indexes. All variables of Parts I and II contributed significantly to the item-total correlation of the instrument. We suggest keeping all variables of the instrument if the investigator is seeking a means to measure the process of mourning.

\section{Regarding criterion validity}

Even before the DSM-5, ${ }^{29}$ Complicated Grief (CG) had diagnostic criteria proposed by independent researchers. Criteria of CG following Prigerson et al., ${ }^{30}$ were measured by items in the Inventory of Traumatic Grief-Revised (ITG-R), ${ }^{3}$ a validated 32 -item questionnaire with high internal consistency (Cronbach's $\alpha=0.92$, sensitivity = 0.93 , specificity $=0.93$ ). Criteria of CG following Horowitz et al.5 were measured by items of the Complicated Grief Module (CGM), ${ }^{5}$ a list of 30 symptoms of CG in the Structured Clinical Interview for DSM-III-R (SCID) module format (Cronbach's $\alpha=0.49-0.58$ ). Horowitz et al., ${ }^{5}$ selected seven items of the CGM as a short set for diagnosing $\mathrm{CG}$, which in its German version achieved sensitivity = 0.60 , specificity $=0.99$, and total predictive value $=0.96$. Forstmeier and Maercker ${ }^{32}$ compared the two diagnostic systems for Complicated Grief and observed that only 2 patients $(0.4 \%)$ of the sample were diagnosed according to the two diagnostic systems. Prigerson et al. APUD Delalibera ${ }^{28}$ created the Prolonged Grief Disorder Instrument (PG-13), validated for the Portugal Portuguese ${ }^{28}$ in a sample with $22.5 \%$ of the population with symptoms of prolonged grief. This validation achieved good internal consistency $(\alpha=0.932)$ and factor analysis showed that the domains 'emotional pain', 'sadness/grief' or 'loss-related episodes of tension' were the strongest indicators of the scale.

For screening complicated grief we may mention the 19-item Inventory of Complicated Grief (ICG) ${ }^{33}$ which with a total score of $\geq$ 25 predicts a range of negative health outcomes ${ }^{33}$ and the Brief Grief Questionnaire (BGQ), ${ }^{26}$ a five-item scale, created as a measure for tracking CG in individuals who sought support after the 9/11 attacks in New York and which was subsequently validated for Japanese. ${ }^{34}$

The DSM- $5^{29}$ adopted two important measures in relation to mourning. First, given that there is insufficient evidence to consider complicated/prolonged grief as a separate diagnosis of major depression, and afraid of excessive prescription of antidepressants to manage the normal and transient sadness of the bereaved, did not considered it as definitive diagnostic entity, putting it in the Appendix as condition for further study. Second, partly because of the lack of evidence of bereavement-related depression being distinct from depression secondary to other life stressors $^{35}$ removed the 'bereavement exclusion'('Not to diagnose a major depressive episode if the symptoms are better accounted for by bereavement') from the diagnostic criteria for major depressive episode, thus encouraging the diagnosis of depression to be made following a bereavement. ${ }^{36}$ The impact of the DSM-5 approach on research is that efforts continue to be made to promote studies that identify and separate complicated/ prolonged grief from depression and post-traumatic stress, as well as the search for instruments of proven accuracy (specificity) and sensitivity (tracking) as a measure of grief. In contrast to the view taken by DSM-5, International Diagnostic Classification of Diseases (ICD11) is proposing a separate diagnosis that recognizes prolonged grief. In clinical practice, according to Bryant, ${ }^{36}$ the accurate classification of these cases may direct them to appropriate treatments. There is initial evidence that antidepressant medication does not address the symptoms of grief effectively; in contrast, there is increasing evidence that grief-focused psychotherapy can be effective. The greater use of prolonged grief as a diagnosis may both limit inappropriate use of antidepressants and facilitate targeted psychotherapeutic interventions that can assist people in overcoming their persistent grief reactions.

To date, there is no standard tool for evaluation of mourning. The TRIG - Brazilian Portuguese version achieved high levels of sensitivity and specificity. It was able to generate a cut-off point for discriminating complicated grief and showed us that using the total score (sum of parts I, II, III and IV), $71.3 \%$ of individuals with and without complicated grief can be correctly classified. And, using logistic regression, it was possible to identify which variables were most important for this differentiation (Table 4).

\section{The validity of constructs}

The EFA showed that each part of the instrument contains correlated variables that converge to form factors (constructs/domains) and which together represent a general index of measurement for mourning. Each factor is named after the emotion or state of the 'I' that best represented it. The factors 'Depression' and 'Rage I' were found in Part I of the instrument. In Part II, the factors 'Pain', 'Rage II' and 'Miss the deceased'. In Part III, the factors 'Consciousness of mourning' and 'Identification with the deceased'. The factor 'Pain' was the major factor in the scale and its most representative items were feelings of emotional pain, sorrow and grief related to the loss. We considered if any of them might be significant in distinguishing between complicated grief from non-complicated grief. The result, from Univariate Logistic Regression was 'yes' to the factors 'Depression' (Part I) and 'Pain' (Part II) as they presented a p-value of 0.033 and 0.003 , respectively. To verify the relationship between the factors found, the CFA was performed taking into account the covariances of all variables in Parts I, II and III among themselves and among the factors. The final adjustment model revealed nine variables highly correlated with each other and were summarized into two major factors called 'Pain' and 'Depression', reaching Cronbach's Alpha of 0.828 with CI $(95 \%)=0.786$ to 0.865 . However, the instrument has 
proved to be more reliable ( $\alpha$-Cronbach of 0.885$)$ if seen as a onedimensional scale, as it is originally described. Futterman et al., ${ }^{11}$ in their study of EFA only for Part II of the TRIG, found three factors: 'Nonacceptance' identical to 'Anger' and 'Emotional Response' and 'Thoughts' both similar to 'Pain' and 'Miss', found in this study.

\section{Limitations}

We did not collect information on the income of the mourner. Thus, we did not analyze the hypothesis confirmed in the original validation of TRIG that females, who in their culture had traditionally been rewarded for dependency on others and who often were financially dependent on their husbands' incomes, would suffer greater life disruption following a death than males, whose life training and culturally stereotyped role behavior were usually encouraged to selfsufficiency. Until the planning of this study the DSM-5 had not been published, which is why we chose clinical criteria for prolonged grief based on the literature and clinical experience. We found that all patients who entered this study would fit the diagnostic criteria for prolonged grief according to the DSM-5.

\section{Conclusion}

TRIG in the Brazilian-Portuguese version was a valid, reliable instrument, with easy and quick application to the Brazilian population. This study contributes to the scope of information that suggests the inclusion of complicated grief as a new diagnosis in DSM-5. As a measure to identify complicated grief, we suggest TRIG with a cutoff point of 104, in partnership with the accurate identification of this condition by clinicians and psychiatrists.

\section{Acknowledgments}

None.

\section{Conflicts of interest}

Author declares there are no conflicts of interest.

\section{Funding}

None.

\section{References}

1. Strobe MS, Stroebe W. The mortality of bereavement. In: Stroebe MS, Stroeb W, et al. (Eds.), Handbook of bereavement: theory, research, and intervention, Cambridge University Press, New York, USA. 1993. p.175-195.

2. Deutsch H. Absence of grief. Psychoanal Quart. 1937;6:12-22.

3. Faschingbauer TR, DeVaul RA, Zissok S. Development of the Texas inventory of grief. Am J Psychiatry. 1977;134(6):696-698.

4. Faschingbauer TR, DeVaul R, Zissok S. Texas revised inventory of grief manual. Honeycomb publishing, Houston, USA. 1981.

5. Horowitz MJ, Siegel B, Holen A, et al. Diagnostic criteria for complicated grief disorder. Am J Psychiatry. 1997;154(7):904-910.

6. Prigerson HG, Frank E, Kasl SV, et al. Complicated grief as a disorder distinct from bereavement-related depression and anxiety: preliminary empirical validation in elderly bereaved spouses. Am J Psychiatry. 1995; 152(1): 22-30.

7. Prigerson HG, Bierhals AJ, Kasl SV, et al. Complicated grief as a disorder distinct from bereavement-related depression and anxiety: a replication study. Am J Psychiatry. 1996;153(11):1484-1486.
8. Prigerson HG, Bridge JB, Maciejewski PK, et al. Traumatic grief as a risk factor for suicidal ideation among young adults. Am J Psychiatry. 1999;156:1994-1995.

9. Prigerson HG, Jacobs S. Traumatic grief as a distinct. In: Stroebe MS, Hansson RO, et al. (Eds), Handbook of bereavement research: consequences, coping, and care. APA press, New York, USA, p. 613645 .

10. Lichtenthal WG, Cruess DG, Prigerson HG. A case for establishing complicated grief as a distinct mental disorder in DSM-V. Clin Psychol Rev. 2004;24(6):637-662.

11. Futterman A, Holland JM, Brown PJ, et al.Factorial validity of the texas revised inventory of grief-present scale among bereaved older adults. Psychol Assess. 2010;22(3):675-687.

12. Langner R, Maercker A. Complicated grief as a stress response disorder: evaluating diagnostic criteria in a german sample. $J$ Psychosom Res. 2005;58(3):235-242.

13. Paulhan I, Bourgeois M. The TRIG (Texas Revised Inventory of Grief) questionnaire. French translation and validation. Encephale. 1995;21(4):257-262.

14. García JAG, Petralanda VL, Manzano MCT, et al. Inventario Texas Revisado de Duelo (ITRD): adaptación al castellano, fiabilidad y validez. Aten Primaria. 2005;35(7):353-358.

15. Yildiz H, Cimete G. Adaptation study of the texas revised inventory of grief. Anadolu Psikiyatry Derg. 2011;12(1):30-36.

16. Barros EN. Tradução e validação do texasrevisedinventoryofgrief (TRIG): aplicação em pais enlutados pela perda de um filho por cancer pediátrico [dissertação]. São Paulo. Fundação Antônio Prudente. 2008.

17. Sechrest L, Fay TL, Zaidi SMH. Problems of translation in cross-cultural research. J Crosscult Psychol. 1972;3(1):41-56.

18. Flaherty JA, Gaviria M, Pathark D, et al. Developing instruments for crosscultural psychiatric research. J Nerv Ment Dis. 1988;176(5):257-263.

19. Ellis BB, Minsel B, Becker P. Evaluation of attitude survey translation: an investigation using item response theory. Int $J$ Psychol. 1989;24(6):665-684.

20. Jorge MR. Adaptação transcultural de instrumentos de pesquisa em saúde mental. Rev Psiquiatrclin. 1998;25(5):233-239.

21. Manzi-Oliveira AB, Balarini FB, Marques LAS, et al. Adaptação de instrumentos de avaliação psicológica: levantamento dos estudos realizados no Brasil de 2000 a 2010. Psico-USF. 2011;16(3):367-381.

22. Borsa JC, Damásio BF, Bandeira DR. Adaptação e validação de instrumentos psicológicos entre culturas: algumas considerações. Paidéia. 2012;22(53):423-432.

23. Fujisawa D, Miyashita M, Nakajima S, et al. Prevalence and determinants of complicated grief in general population. J Affect Disord. 2010;127(1-3):352-358.

24. Kersting A, Brahler E, Glaesmer H, et al. Prevalence of complicated grief in a representative population-based sample. $J$ Affect Disord . 2011;131(1-3):339-343.

25. Newson RS, Boelen PA, Hek K, et al. The prevalence and characteristics of complicated grief in older people. J Affect Dsisord. 2011;132(1-2):231-238.

26. Shear KM, Jackson CT, Essock SM, et al. Screening for complicated grief among Project Liberty service recipients 18 months after September 11, 2001. Psychiatr Serv. 2006; 57(9):1291-1297.

27. Zissok S. Unresolved Grief. In: Zissok (Ed.), Biopsychosocial aspects of bereavement editor. American psychiatric press, Washington DC, USA. $1987 ; 2: 21-34$ 
28. Delalibera M, Coelho A, Barbosa A. Validação do instrumento de avaliação do luto prolongado para a população portuguesa. Acta Med Port. 2011;24:935-42.

29. American Psychiatry Association. Diagnostic and statistical manual of mental disorders DSM-5. (5th edn), American Psychiatric Association, Washington, USA. 2013.

30. Prigerson HG, Shear MK, Jacobs SC, et al. Consensus criteria for traumatic grief: a preliminary empirical test. Brit J Psychiat. 1999; 174:67-73.

31. Prigerson HG, Jacobs SC. Traumatic grief as a distinct disorder: rationale, consensus criteria, and a preliminary empirical test. In: Stroebe MS, Hansson RO, et al. (Eds.), Handbook of Bereavement Research. APA, Washington, DC, USA. 2001. p.613-645.
32. Forstmeier S, Maercker A. Comparison of two diagnostic systems for Complicated Grief. J Affect Dsisord. 2007;99(1-3):203-211.

33. Prigerson HG, Maciejewski PK, Reynolds CF 3rd, et al. Inventory of Complicated Grief: a scale to measure maladaptive symptoms of loss. Psychiat Res. 1995;59(1-2):65-79.

34. Ito M, Nakajima S, Fujisawa D, et al. Brief Measure for screening complicated grief: realiability and discriminant validity. Plos One. 2012;7(2):e31209.

35. Zissok S, Corruble E, Duan N, et al. The bereavement exclusion and DSM-5. Depression Anxiety. 2012;29(5):425-443.

36. Bryant RA. Prolonged grief: where to after diagnostic and statistical manual of mental disorders, 5th edition? Curr Opin Psychiatry. $2014 ; 27(1): 21-26$ 